\title{
Determination of effective specific heat capacity of interior plaster containing phase change materials
}

\author{
Václav Kočí ${ }^{1}$, Jiři Maděra ${ }^{1}$, and Robert Černý $^{1}$ \\ ${ }^{1}$ Department of Materials Engineering and Chemistry, Faculty of Civil Engineering, Czech \\ Technical University in Prague, Thákurova 7/2077, 16629 Prague 6, Czech Republic
}

\begin{abstract}
A precise technique for determination of effective specific heat capacity of building materials is presented within this paper. The applicability of the technique is demonstrated on a PCM-enhanced plaster, being characterized by a phase change between 15 and $30{ }^{\circ} \mathrm{C}$. The effective specific heat capacity is determined by means of inverse analysis of calorimetric data using computational model of the device. The identified effective specific heat capacity values reached up to $1890 \mathrm{~J} \cdot \mathrm{kg}^{-1} \cdot \mathrm{K}^{-1}$ when cooled and $1580 \mathrm{~J} \cdot \mathrm{kg}^{-1} \cdot \mathrm{K}^{-1}$ when heated. Using this quantity in simulation of thermal performance, the PCM-enhanced plaster showed to have a promising potential to be used in buildings' interiors as a thermal regulator to stabilize inner environment as it contributed to a thermal oscillation decrease by up to $2.5^{\circ} \mathrm{C}$
\end{abstract}

\section{Introduction}

Recent research of interior plasters containing phase change materials (PCM) have revealed a great potential of these materials to contribute to improvement of thermal stability of building environment [1-3] or to achieve energy savings [2, 4, 5]. The development of such plasters is very specific and tailored to a particular solution by adjusting their phase transition interval and latent heat $[6,7]$. Experimental analyses of thermal properties and assessment of thermal performance of newly developed plasters represent crucial requirements that should be met before their practical application.

Computational modelling belongs among the most effective techniques for assessment of building materials and structures as it can provide immediate results of any nature that practically does not require any costs. An assessing of thermal performance of building materials usually requires only basic physical, heat storage and transport properties which are easy to be gathered. Moreover, the phase transition process, typical for PCM, can be involved in the modelling using simple

\footnotetext{
${ }^{1}$ Corresponding author: vaclav.koci@,fsv.cvut.cz
} 
fix-domain method that introduces so called effective specific heat capacity incorporating the phase change enthalpy. In this paper, determination of effective specific heat capacity is done by means of inverse analysis of differential scanning calorimetry (DSC) results. The obtained data are then used to assess and compare the thermal performance of plaster with and without PCM.

\section{Materials and methods}

\subsection{Materials}

The plasters investigated within this paper were developed within the previous research conducted by Forrt et al. [8]. In their study, they used a commercial limecement plaster, which is further denoted as REF, and modified it using dodecanol/diatomite composite acting like the PCM. The plaster was composed of dry mixture $(3 \mathrm{~kg})$, water $(1.15 \mathrm{~kg})$ and the PCM $(1.2 \mathrm{~kg})$. The modified plaster is further marked as DDPCM16 in accordance with the original labelling proposed by Forrt et al. [8]. The basic physical, heat transport and storage properties of the plasters are summarized in Table 1.

Table 1. Properties of plasters.

\begin{tabular}{|c|c|c|c|c|}
\hline & Bulk density & Porosity & $\begin{array}{c}\text { Thermal } \\
\text { conductivity }\end{array}$ & $\begin{array}{c}\text { Specific heat } \\
\text { capacity }\end{array}$ \\
\hline $\mathrm{REF}$ & $1572 \mathrm{~kg} \cdot \mathrm{m}^{-3}$ & $34.9 \%$ & $0.54 \mathrm{~W} \cdot \mathrm{m}^{-1} \cdot \mathrm{K}^{-1}$ & $1014 \mathrm{~J} \cdot \mathrm{kg}^{-1} \cdot \mathrm{K}^{-1}$ \\
\hline $\mathrm{DDPCM} 16$ & $1398 \mathrm{~kg} \cdot \mathrm{m}^{-3}$ & $36.2 \%$ & $0.49 \mathrm{~W} \cdot \mathrm{m}^{-1} \cdot \mathrm{K}^{-1}$ & $998 \mathrm{~J} \cdot \mathrm{kg}^{-1} \cdot \mathrm{K}^{-1}$ \\
\hline
\end{tabular}

\subsection{Inverse analysis of calorimetric data}

Using a computational model captured in Fig. 1 [9], inverse analyses of DSC experimental outputs produced by Fořt et al. [8] were performed. Main objective of these analyses was to eliminate signal delay, setup influence and other uncertainties that accompany the experimental measurement procedure. Operating with material properties, the model is able to identify and reproduce the ongoing heat processes in the device during the measurement. Unlike the real device, it can then extract and evaluate data directly upon the real sample temperature, not upon the temperature recorded on thermocouples outside the sample. This advantage results in elimination of signal shift or delay and elimination of partial heat consumption on the way between the sample and the thermocouple. 


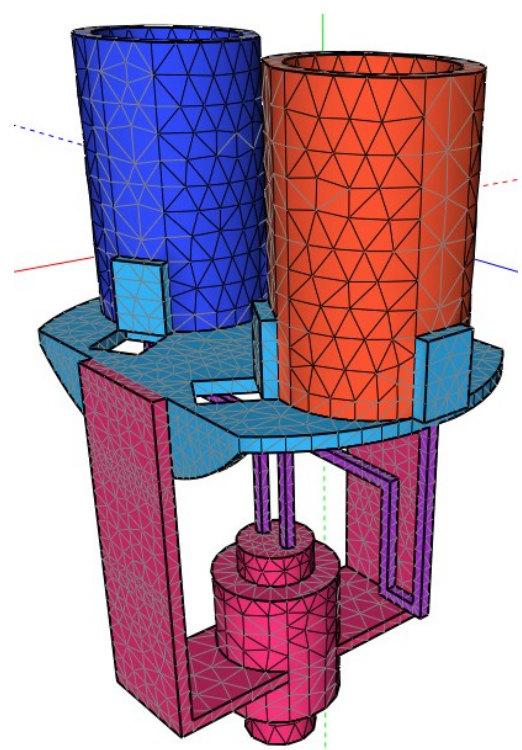

Fig. 1. Computational model of the DSC rod with the crucibles.

As the output of computational modelling, the effective specific heat capacities of the plasters were obtained as a function of temperature. The effective curves contain also phase change enthalpies which can be therefore easily included in any mathematical model in form of the material parameter (fix-domain method [10]).

\subsection{Computational modelling of thermal performance}

To quantify a contribution of PCM in the plaster, thermal performance of REF and DDPCM16 plasters is compared. For that purpose, a response of the plasters to cyclic temperature step changes between 0 and $40{ }^{\circ} \mathrm{C}$ is evaluated by means of twodimensional computational modelling using the computer code HMS [11]. There is a diffusion type of mathematical model for coupled heat and moisture transport included in the code [12], however regarding the problem type, the moisture transport was disabled in the computations. A scheme of the solved detail including a computational mesh is depicted in Fig. 2. Each exposure took one hour. 


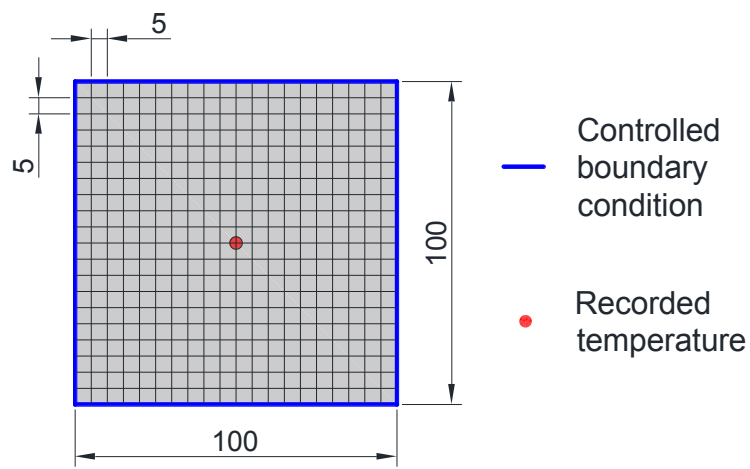

Fig. 2. Computational model of the DSC rod with the crucibles.

\section{Results and discussion}

\subsection{Effective specific heat capacity of the phase change}

Reaching an agreement of computational and experimental outputs recorded on thermocouples, the computational model identified effective specific heat capacity of DDPCM16 as a function of temperature for both heating and cooling processes. The agreement of heat power curves is shown on the left hand side in Fig. 3. Here, experimental outputs are depicted using solid lines while the computational results are plotted using dotted lines. The corresponding effective specific heat capacities are shown on the right hand side in Fig. 3.

It can be observed that the computational outputs agree very well with the experimental data as the mean difference accounts for $0.0035 \mathrm{~mW} \cdot \mathrm{mg}^{-1}$ for cooling and $0.0046 \mathrm{~mW} \cdot \mathrm{mg}^{-1}$ for heating. The computational outputs were obtained using effective specific heat capacities depicted in Fig. 3, where the highest value reached $1889.76 \mathrm{~J} \cdot \mathrm{kg}^{-1} \cdot \mathrm{K}^{-1}$ at $22{ }^{\circ} \mathrm{C}$ for cooling and $1580.17 \mathrm{~J} \cdot \mathrm{kg}^{-1} \cdot \mathrm{K}^{-1}$ at $26^{\circ} \mathrm{C}$ for heating, respectively. Such peak top values are comparable to those presented by other researchers regarding to the different plaster composition. For instance Pavlík et al. [13] reported the maximal effective specific heat capacity of plaster containing paraffinic wax to be $\sim 2200 \mathrm{~J} \cdot \mathrm{kg}^{-1} \cdot \mathrm{K}^{-1}$, Theodoridou et al. [14] determined effective specific heat capacity of PCM-enhanced plaster to be $\sim 1020 \mathrm{~J} \cdot \mathrm{kg}^{-1} \cdot \mathrm{K}^{-1}$. 

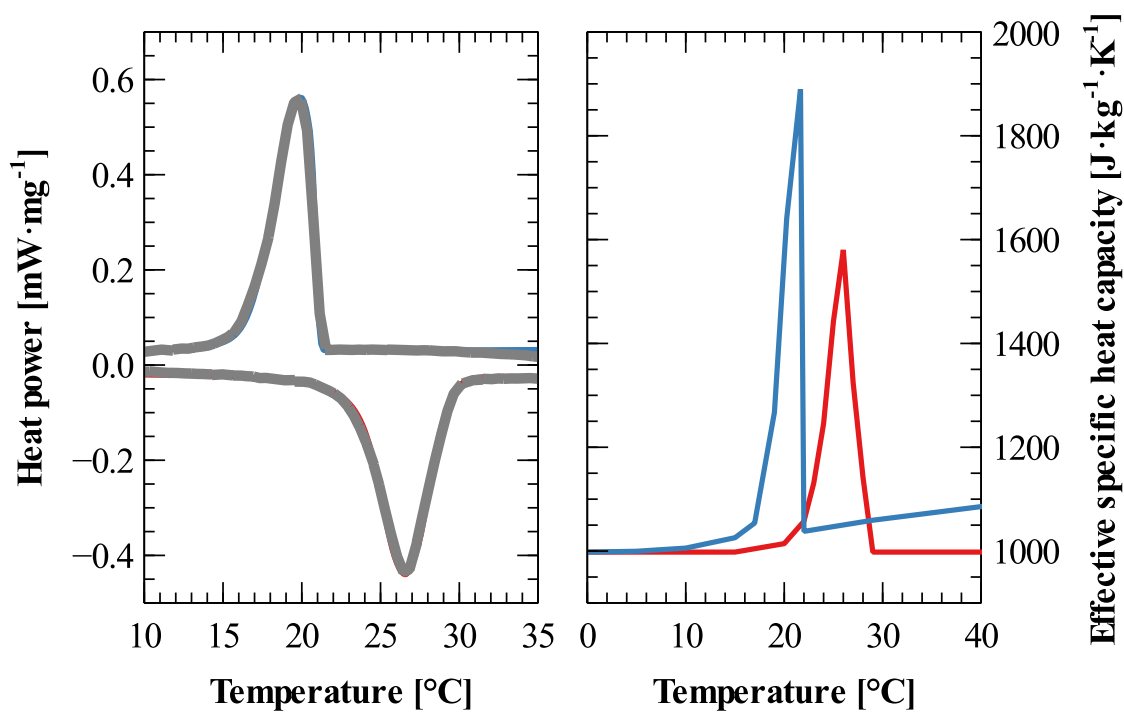

Fig. 3. Agreement of experimental and computational outputs (left) using effective specific heat capacities of DDPCM16 (right).

\subsection{Evaluation of thermal performance}

According to results of thermal performance (see Fig. 4), an influence of PCM additives in the plaster is obvious, being evinced by temperature differences of particular plasters in the studied point. 


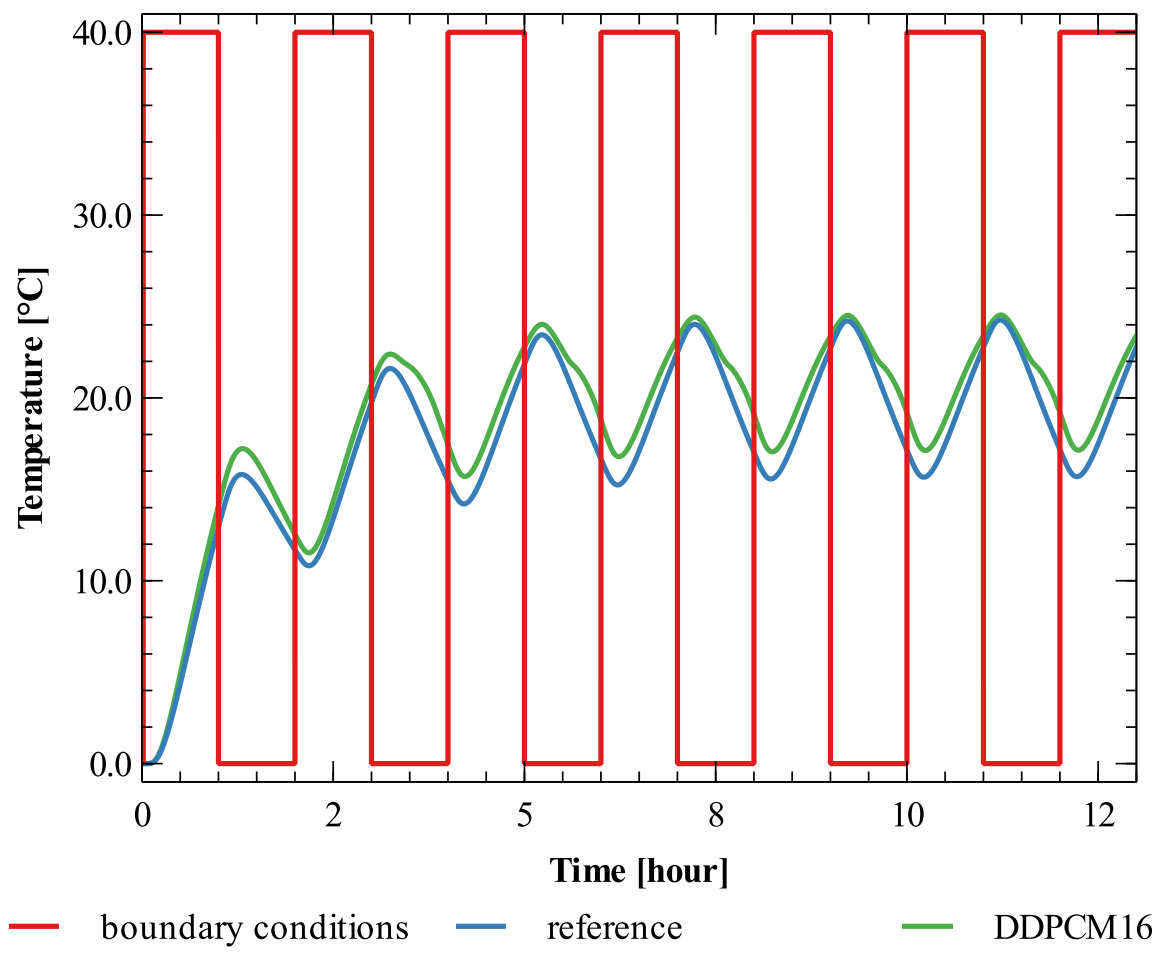

Fig. 4. Thermal performance of plasters.

The differences originate from various thermal responses to the temperature step changes, as the DDPCM16 has higher heat capacity due to ongoing phase changes between 15 and $30{ }^{\circ} \mathrm{C}$. Since the effective specific heat capacity is higher for cooling, the highest temperature difference, compared to REF, is found on decreasing temperature branches. The found temperature shift during the heating/cooling course accounted for up to $2.46{ }^{\circ} \mathrm{C}$, which makes DDPCM16 promising to be used as an interior plaster for moderation of indoor environment. When compared to other research findings, higher temperature differences were reported e.g. by Heim and Wieprzkowicz [15] or Rao et al. [7], which may reach up to $6{ }^{\circ} \mathrm{C}$ depending on type of structure, type of PCM or boundary conditions applied.

\section{Conclusions}

Thermal performance of a plaster containing phase change materials was assessed in this paper using computational modelling. The course of phase change is simulated using the effective specific heat capacity that includes phase change enthalpy and is therefore simple to be implemented in any mathematical model for description of heat transport that operates with standard thermal quantities.

The effective specific heat capacity was obtained by means of inverse analysis of a calorimetric experiment. The exact replica of a differential scanning calorimeter was constructed, calibrated and verified. Subsequently it was exploited to identify exact ongoing heat processes in the measuring crucible that produce identical 
outputs on thermocouples outside the crucibles similarly to the real device. This technique can be considered as more precise as it neglects signal shift and delay ascribed to partial heat consumption.

It was found, that effective specific heat capacity of the studied PCM-enhanced plaster may reach up to $1890 \mathrm{~J} \cdot \mathrm{kg}^{-1} \cdot \mathrm{K}^{-1}$ when cooled and $1580 \mathrm{~J} \cdot \mathrm{kg}^{-1} \cdot \mathrm{K}^{-1}$ when heated. The found effective specific heat capacity curves gave almost identical heat power outputs as the real device, differing only by $0.046 \mathrm{~mW} \cdot \mathrm{mg}^{-1}$ at most which confirmed very high accuracy of the model. Analysing thermal performance of the plaster it was demonstrated on the selected task, the PCM contained attenuated temperature fluctuations of the plaster, when exposed to temperature step change on the boundaries, as it contributed to decrease of the thermal oscillation by up to 2.5 ${ }^{\circ} \mathrm{C}$. It makes the plaster promising to be used in buildings' interiors as a thermal regulator to stabilize inner environment.

This project has been supported by the Czech Science Foundation under Project No 1701365 S.

\section{References}

1. A. Sari, A. Bicer, A. Karaipekli, F.A. Al-Sulaiman, Sol Energ Mater Sol C 174, $523(2018)$

2. F. Ascione, N. Bianco, R.F. De Masi, F. de' Rossi, G.P. Vanoli, Appl Energ 113, 990 (2014)

3. C. Voelker, O. Kornadt, M. Ostry, Energ Build 40, 937 (2008)

4. A. Karaipekli, A. Sari, Sol Energ Mater Sol C 149, 19 (2016)

5. M. Kheradmand, M. Azenha, J.P. Castro-Gomes, J.L.B. Aguiar, P I Civil EngConstr Mater 171, 117 (2018)

6. Y. Konuklu, M. Ostry, H.O. Paksoy, P. Charvat, Energ Build 106134 (2015)

7. V.V. Rao, R. Parameshwaran, V.V. Ram, Energ Build 158, 95 (2018)

8. J. Fort, A. Trnik, M. Pavlikova Z. Pavlik, R. Cerny, Int J Thermophys 39, 11 (2018)

9. V. Koci, J. Madera, A. Trnik, L. Scheinherrova, R. Cerny, AIP Conf Proc 1988, $020021(2018)$

10. J. Crank, Free and moving boundary problems (Calverdon Press, Oxford, 1984)

11. V. Koci, J. Koci, J. Madera, Z. Pavlik, X. Gu, W. Zhang, R. Cerny, J Build Phys 41, 497 (2018)

12. J. Madera, J. Koci, V. Koci V, J. Kruis, Adv Eng Softw 113, 47 (2017)

13. Z. Pavlik, A. Trnik, J. Ondruska, M. Keppert, M. Pavlikova, P. Volfova, V. Kaulich, R. Cerny, Int J Thermophys 34, 851 (2013)

14. M. Theodoridou, L. Kyriakou, I. Ioannou, Enrgy Proc 97, 539 (2016)

15. D. Heim, A. Wieprzkowicz, Appl Sci-Basel 8, 13 (2018) 